\title{
Revascularization as a treatment to improve renal function
}

\section{Helen V Alderson \\ James P Ritchie \\ Philip A Kalra}

The University of Manchester, Manchester Academic Health Sciences Centre, Vascular Research Group, Department of Renal Medicine, Salford Royal NHS Foundation Trust, Salford, UK
Correspondence: Philip A Kalra Department of Renal Medicine, Salford Royal Hospital, Salford, Greater Manchester, M8 8HD, UK Email philip.kalra@srft.nhs.uk
This article was published in the following Dove Press journal: International Journal of Nephrology and Renovascular Disease 20 February 2014

Number of times this article has been viewed

\begin{abstract}
An aging atherosclerosis-prone population has led to an increase in the prevalence of atherosclerotic renovascular disease (ARVD). Medical management of this disease, as with other atherosclerotic conditions, has improved over the past decade. Despite the widespread availability of endovascular revascularization procedures, there is inconsistent evidence of benefit in ARVD and no clear consensus of opinion as to the best way to select suitable patients for revascularization. Several published randomized controlled trials have attempted to provide clearer evidence for best practice in ARVD, but they have done so with varying clarity and success. In this review, we provide an overview of ARVD and its effect on renal function. We present the currently available evidence for best practice in the management of patients with ARVD with a particular focus on revascularization as a treatment to improve renal function. We provide a brief overview of the evidence for revascularization in other causes of renal artery stenosis.
\end{abstract}

Keywords: renal artery stenosis, revascularization, atherosclerotic renovascular disease, fibromuscular dysplasia

\section{Introduction}

In the Western world, over $90 \%$ of cases of renal artery stenosis (RAS) are caused by atherosclerotic renovascular disease (ARVD). This is a heterogeneous condition that can present in various ways, from clinically silent disease to flash pulmonary edema or anuric acute kidney injury (AKI). Strong associations exist between the presence of ARVD and other atherosclerotic diseases, hypertension, and chronic kidney disease (CKD). An aging population means that this is an increasing problem in the Western world. Endovascular renal revascularization procedures have been available for over 3 decades. Despite an extensive literature of case reports and randomized controlled trials (RCTs), there is little robust evidence for revascularization, even in clinical scenarios where international guidelines support an interventional approach. However, interpretation of the published literature is confounded by the complex pathogenesis and the range of clinical presentations of ARVD. As such, the debate over merits of intervention continues. Although ARVD is the most common cause of RAS, other conditions are recognized, with fibromuscular disease being the most common of these in the Western world. Here, the clinical consensus regarding revascularization is more positive. This review focuses on revascularization for ARVD with separate, more limited consideration given to other causes of RAS. 


\section{Epidemiology of ARVD}

Assessing the true population prevalence of ARVD is difficult; it may be a clinically silent condition and there is no screening program in place. Where prevalence studies have been published, confounding due to high rates of co-existent diabetes, hypertension, and vascular comorbidity is often present. The effect of comorbidity can be demonstrated by comparing the prevalence rate of $20 \%$ ( $95 \%$ confidence interval [CI] 15.4-25.5) seen in patients with diabetes and hypertension ${ }^{1}$ to the figure of $6.8 \%$ seen in a Doppler ultrasound screening study of 834 community-based elderly 'free-living' individuals in Forsyth county, NC, USA. ${ }^{2}$ The incidence of ARVD has appeared to vary over time, most likely due to evolving physician awareness and access to diagnostic tools. The largest data are drawn from interrogation of the US Medicare 5\% denominator file. Here, in the period 1999-2001, the incidence of ARVD was 3.7/1,000 patient-years in patients aged over 67 years. ${ }^{3}$ Rates of diagnosis increased until the mid-2000s, ${ }^{4}$ due perhaps to the increasing enthusiasm for undertaking revascularization procedures before the results of RCTs into the condition were available. Although no subsequent analysis of the Medicare data has been undertaken, United States Renal Data System (USRDS) reports have since shown a reduction in cases of end-stage kidney disease (ESKD) secondary to ARVD (reduction from $1.7 \%$ to $1.3 \%$ between 2004 and 2009). ${ }^{5}$

Although ARVD is the most common cause of RAS in the West (with post-vasculitic stenosis the most common cause in parts of Asia), there are no robust data to suggest ethnic variation in prevalence. In the population screening study discussed above, equal proportions of White and African American subjects had significant disease, ${ }^{2}$ and in a retrospective analysis of over 300 patients screened for ARVD ( $40 \%$ non-White), Caucasian ethnicity was not identified as an independent predictor for the presence of RAS. ${ }^{6}$ As no study has compared Caucasian and Asian patients, it is impossible to pass precise comment. However, a markedly lower proportion of Japanese patients with other macrovascular disease have abnormal renal vessels. ${ }^{7}$

\section{Prognosis in ARVD Mortality}

Mortality rates are high in ARVD, with patients six times more likely to die of a cardiovascular event than progress to ESKD. The earlier Medicare analysis showed that annual mortality rates in patients with ARVD (16.3\%) were almost three times greater than general Medicare patients without the condition. ${ }^{3}$ Improved understanding of how best to manage these patients has likely contributed to reducing this gap, with an average annual mortality rate of $8 \%$ in ARVD patients in the most recently published RCT data. ${ }^{8}$ Several series have demonstrated that the presence of ARVD is an adverse prognostic factor independent of the presence of other atherosclerotic diseases. In coronary artery disease, a 1.5-times higher risk for death is associated with the presence of ARVD, ${ }^{9}$ whereas it indicates a 3-times higher risk in patients with peripheral vascular disease..$^{10}$ This relationship appears to exist in both directions, with ARVD patients investigated for other macrovascular disease having an increased 4-year mortality rate where a greater degree of extra-renal disease exists. ${ }^{11}$

Data regarding survival in patients with ARVD who reach dialysis are conflicting. A single-center study of over 680 hemodialysis patients described significantly increased mortality following initiation of dialysis in ARVD patients compared with other primary disease groups. ${ }^{12}$ However, another large-scale Medicare and USRDS analysis noted a significantly reduced risk for death following initiation of dialysis in patients with ARVD when adjusted for comorbid conditions. ${ }^{13}$ It remains unclear whether the apparent increase in risk described in the initial study is simply a reflection of comorbid atherosclerotic disease, or if the reduced risk in the latter study is a limitation of the coded data that were available.

\section{Renal function}

With current management, the average annual rate of loss of renal function in ARVD in both RCT and 'real-world' data is between 1 and $2 \mathrm{~mL} / \mathrm{min} / 1.73 \mathrm{~m}^{2} /$ year, ${ }^{8,14}$ with approximately $4 \%$ of patients progressing to renal replacement therapy each year. ${ }^{8} 15$ Registry data suggest that ARVD is the primary disease in $6.7 \%$ of incident UK dialysis patients. ${ }^{16}$ However, the pathogenesis of renal parenchymal damage in ARVD is complex; the extent of renal dysfunction is not explained solely by the degree of RAS. Historic observational studies have shown that renal artery lesions commonly progress, ${ }^{17}$ although this has been markedly attenuated following the introduction of statins ${ }^{18}$ However, there is no clear relationship between vascular anatomy and rate of change in renal function. Cheung et al ${ }^{19}$ studied 142 patients with unilateral renal artery occlusion and demonstrated that there was no relationship between contralateral renal artery anatomy and baseline renal function or rate of change in renal function. Intra-renal ischemia, microvascular disruption, ${ }^{20}$ and associated renal atrophy ${ }^{21}$ appear to be more important than the degree of stenosis in determining functional outcomes in ARVD. 
The identification of patients with 'hibernating parenchyma' may help to select those who are likely to benefit from revascularization. This term was first coined by Tuttle ${ }^{22}$ and is used to distinguish those kidneys that may improve with revascularization from those that have suffered irreversible parenchymal damage, and that show no improvement.

\section{Treatment for ARVD Medical therapy}

There is a limited evidence base for the medical management of patients presenting with ARVD. Treatment with angiotensin blockade ${ }^{23,24}$ and lipid-lowering therapy ${ }^{25}$ is accepted as a minimum standard of care, and there is consensus that other vascular risk reduction measures should be applied. Given differences in medical therapy within and between published RCT data, direct comparison between studies is not practical. However the Cardiovascular Outcomes in Renal Atherosclerotic Lesions (CORAL) trial included standardized medical therapy of anti-platelet agent and lipidlowering therapy, with angiotensin II blockade as first-line anti-hypertensive therapy. ${ }^{26}$

\section{Revascularization}

Surgical revascularization for ARVD has effectively been consigned to history, at least in cases without complicated anatomy, as percutaneous intervention has been shown to produce comparable angiographic results ${ }^{27}$ without suffering the $10 \%$ mortality rate described with open reconstruction. ${ }^{28}$ Standard practice is now accepted to be percutaneous angioplasty with bare metal stenting (percutaneous transluminal renal angioplasty with stenting [PTRAS]), with stents significantly reducing rate of restenosis compared with angioplasty alone, especially for ostial lesions. ${ }^{29-31}$ Although PTRAS is considered relatively safe in expert hands, around $3 \%$ of patients experience a serious complication such as major hemorrhage or dissection, and less serious complications such as a transient deterioration in renal function or groin hematoma may occur in around $10 \%$ of cases. ${ }^{32}$ In light of these procedural risks, it is important to determine which patients are most likely to benefit from revascularization procedures and to perform them on this select cohort rather than in all patients with ARVD. Historical registry data indicate that revascularization procedures were performed in around $16 \%$ of cases of ARVD, ${ }^{3}$ although this figure has fallen markedly in light of negative trials into PTRAS..$^{33}$ What remains unclear is which patients are currently being revascularized. Whilst published trials have considered change in blood pressure and renal function as primary endpoints, with death and cardiovascular events as secondary endpoints, international guidelines consider presentation with flash pulmonary edema, refractory hypertension, and progressive CKD as possible indications for renal artery stenting. ${ }^{34}$ Whilst there is support for PTRAS in patients presenting with flash pulmonary edema ${ }^{35}$ and oligo-anuric AKI ${ }^{36}$ support for these guidelines is not universal..$^{37}$ Furthermore, arguments exist to support PTRAS to enable the institution of angiotensin-converting enzyme inhibitors ${ }^{38}$ or to treat chronic heart failure. ${ }^{39}$

\section{Revascularization and its effect on renal function Progression of CKD}

A number of case series and RCTs have now examined the relationship between progression of CKD and revascularization in ARVD. Although some case series showed a trend towards reduced rates of decline in renal function following endovascular revascularization procedures, ${ }^{29,40}$ other studies have suggested less convincing evidence of benefit. ${ }^{41,42}$ Beutler et $\mathrm{a}^{43}$ were only able to demonstrate benefit in those with declining renal function pre-intervention. The uncertainty and conflicting findings of these series paved the way for a number of RCTs of revascularization in ARVD.

Prior to the landmark Angioplasty and STenting for Renal Artery Lesions (ASTRAL) study, ${ }^{8}$ there were five published RCTs comparing percutaneous renal artery revascularization with medical therapy in patients with ARVD. ${ }^{31,44-47}$ Renal function varied from normal to moderate CKD, and hypertension was invariably present. These trials were all small, the largest having only 106 patients, and follow-up periods were short. The earlier trials have looked at angioplasty rather than stent insertion and were inadequately powered to assess major functional outcomes. These trials failed to ascertain whether or not revascularization is superior to medical therapy in the management of RAS and to provide clearer indications for its use. A later meta-analysis of the first three RCTs ${ }^{44-46}(n=210)$ showed that, although there was no benefit in blood pressure at 6 months, there was a greater mean improvement in blood pressure in those who underwent angioplasty. ${ }^{48}$ The Dutch-led Stent Placement in Patients With Atherosclerotic Renal Artery Stenosis and Impaired Renal Function (STAR) study was published just prior to ASTRAL. A high proportion of patients randomized to stenting did not receive the procedure and no differences were observed in terms of blood pressure control or renal function. ${ }^{47}$ Hence, none of these studies has been able to demonstrate a significant difference in progression of renal function in patients receiving medical therapy compared 
with those undergoing revascularization procedures. These trials are summarized in Table 1.

The ASTRAL trial was designed to try and determine whether revascularization is of benefit in ARVD. A total of 806 patients with ARVD (average 76\% stenosis) were recruited and randomized to either medical therapy alone or medical therapy plus endovascular revascularization. Median follow-up was 33.2 months, with a minimal follow-up of 12 months for all patients. The primary endpoint was change in renal function, with change in blood pressure, cardiovascular events, renal events, and all-cause mortality the main secondary endpoints. The study found no difference in the primary endpoint of change in renal function between the two groups. Similarly, blood pressure fell equally in both groups and there was no difference in cardiovascular events or mortality between the two groups. The ASTRAL trial concluded that endovascular revascularization does not improve renal function, blood pressure control, cardiovascular events, or mortality in patients with $\mathrm{ARVD}^{8}$ (Figures 1 and 2).

However, the ASTRAL trial had limitations. Importantly, patients were only eligible for enrollment if their managing clinician was uncertain about whether or not they would benefit from revascularization. Although impossible to quantify, it is probable that patients presenting with ARVD and rapidly deteriorating renal function or hypertension that was difficult to control were not enrolled in this study but rather were referred directly for revascularization by their clinicians outside of the trial.

ASTRAL has been criticized on a number of counts. First, there was no centralized verification of the degree of RAS in enrolled patients (so some lesions may have been overestimated). Moreover, the clinical equipoise of the trial meant that patients with normal renal function and relatively minor disease were included. Critics of the trial felt the inclusion of such low-risk patients may have led to bias in the results, as this group of patients would be unlikely to demonstrate progressive renal decline regardless of whether or not revascularization procedures were undertaken. ${ }^{49,50}$ However, post hoc analysis of subgroups with severe disease also failed to demonstrate significant improvement with stenting, leading some to assert that benefits previously attributed to endovascular revascularization could be achieved with best medical management. ${ }^{51}$ Whatever the criticisms of ASTRAL may be, it showed that there is little clinical benefit to be gained from revascularization in patients presenting with stable renal function and ARVD and certainly little to justify the procedural risks in this group. The optimal management in other groups is still an area for ongoing debate and research.
The publication of the ASTRAL results has led to a major change in practice, with the rate of renal revascularization falling to $30 \%$ of the pre-trial results in the UK, with similar reductions in the USA. Despite its shortcomings, ASTRAL demonstrated that, in most patients, stenting for ARVD does not benefit renal function. The continued uncertainty regarding other clinical outcomes, such as major cardiovascular and renal events, was the basis for the design of the recently published CORAL trial. ${ }^{26,52}$

CORAL opened in 2004 and completed recruitment in 2012. The trial randomized 947 patients with $>60 \%$ atherosclerotic RAS to standardized medical management or medical management plus endovascular revascularization. The degree of RAS in all patients was centrally verified in a core radiology laboratory. In order to determine benefit in relation to major renal and cardiovascular endpoints, there was a composite of cardiovascular and renal death, cardiovascular events (myocardial infarction [MI], stroke, congestive cardiac failure), increasing serum creatinine, or initiation of renal replacement therapy. ${ }^{26}$ Over a mean follow-up of 43 months, there was no difference in the rate of the composite endpoints between the stent plus medical therapy and the medical therapy alone group (35.1\% and $35.8 \%$, respectively), hazard ratio with stent 0.94 (95\% CI $0.76-1.17 ; P=0.58)$. In the subgroup of patients with more severe stenosis $(>80 \%)$, there was also no benefit with stenting in addition to medical therapy. Furthermore, there was no difference in the component endpoints or all-cause mortality between the two groups. The CORAL trial was able to conclude that stenting placement for ARVD does not confer benefit with respect to clinical events when added to medical therapy in those patients with ARVD and hypertension or CKD. ${ }^{52}$

\section{$\mathrm{AKI}$}

There are case reports of rescue from dialysis of patients presenting with anuric AKI secondary to ARVD. ${ }^{36}$ The general consensus of opinion is in favor of intervention in these individuals, although no further evidence base exists to support this. It is possible that patients presenting in this way fall into two groups. First there are those patients presenting with an acute renal artery occlusion or very high-grade RAS; in these individuals urgent revascularization is needed in order to restore renal blood flow and perfusion. In other patients, there may be a background of chronic ischemia and then an acute insult that results in an episode of AKI. These kidneys are chronically under-perfused and ischemic and therefore may be less likely to respond to an intervention. 


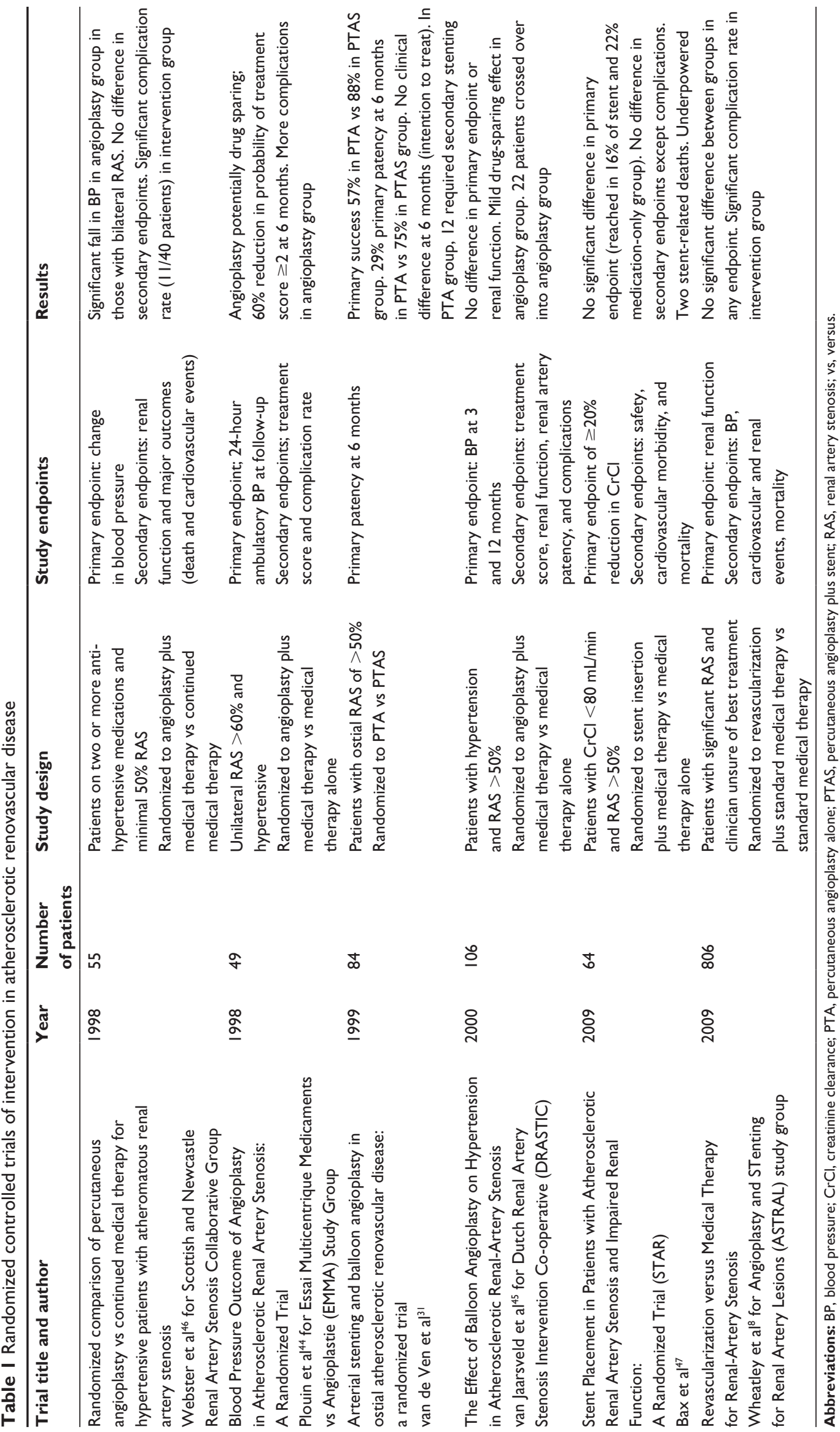



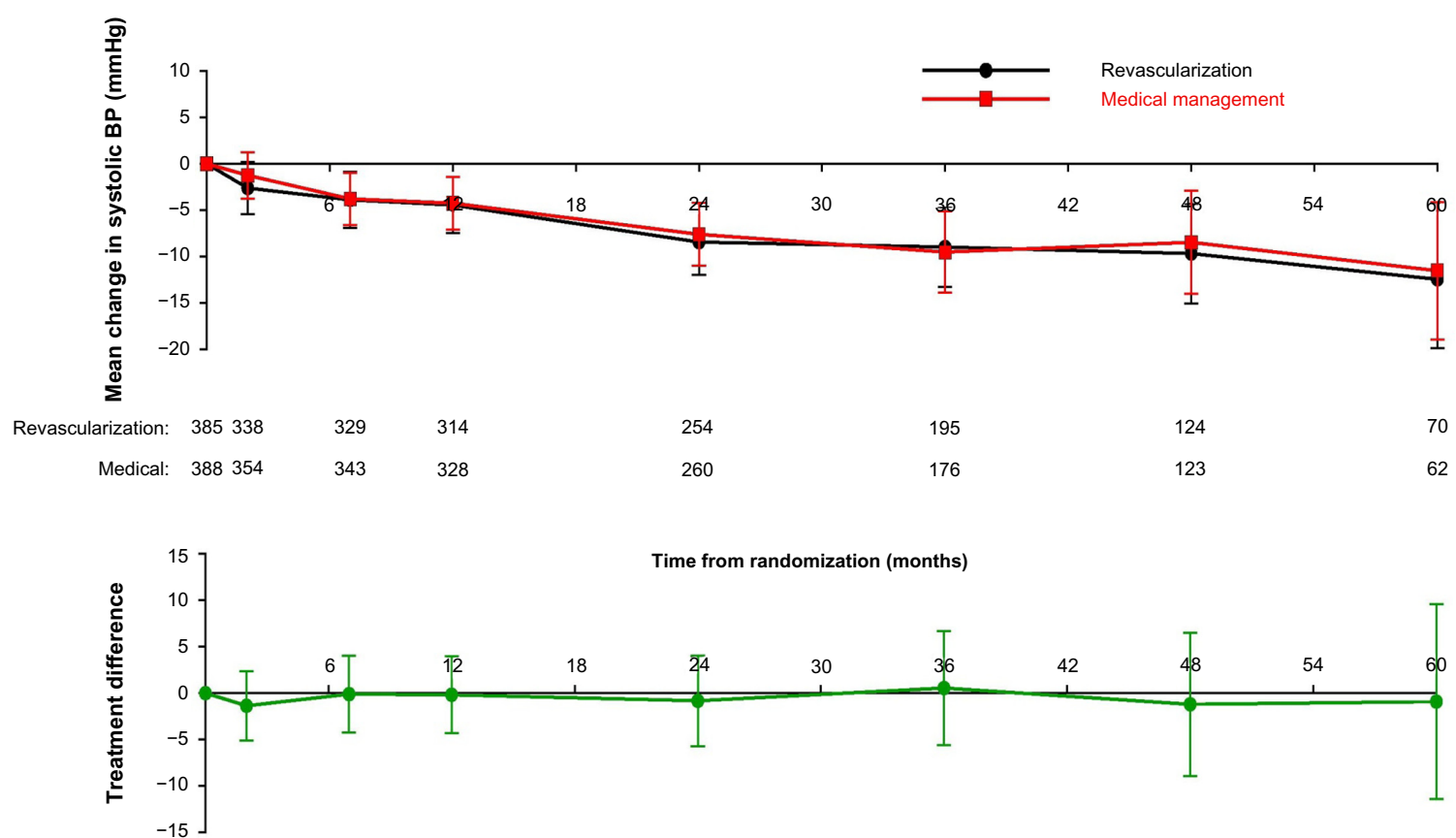

Figure I Mean change in systolic blood pressure $(\mathrm{mmHg})$ over time with revascularization and medical therapy in ASTRAL.

Note: Data from the ASTRAL study. ${ }^{8}$

Abbreviations: ASTRAL, Angioplasty and STenting for Renal Artery Lesions; BP, blood pressure.

\section{Rapidly declining renal function}

The published guidelines support revascularization in patients with rapidly declining renal function, but the latter has not been consistently defined, and there remains very little evidence of benefit to support such an approach. The ASTRAL trial examined a subgroup of 96 patients with rapidly declining renal function (defined as $20 \%$ and/or
$100 \mu \mathrm{mol} / \mathrm{L}$ increase in serum creatinine over 1 year). Although at follow-up those patients that underwent revascularization had a lower serum creatinine than those on standard medical therapy, this difference was not statistically significant. ${ }^{8}$

In a single-center assessment of 127 patients undergoing revascularization outside of the ASTRAL trial in a UK center,
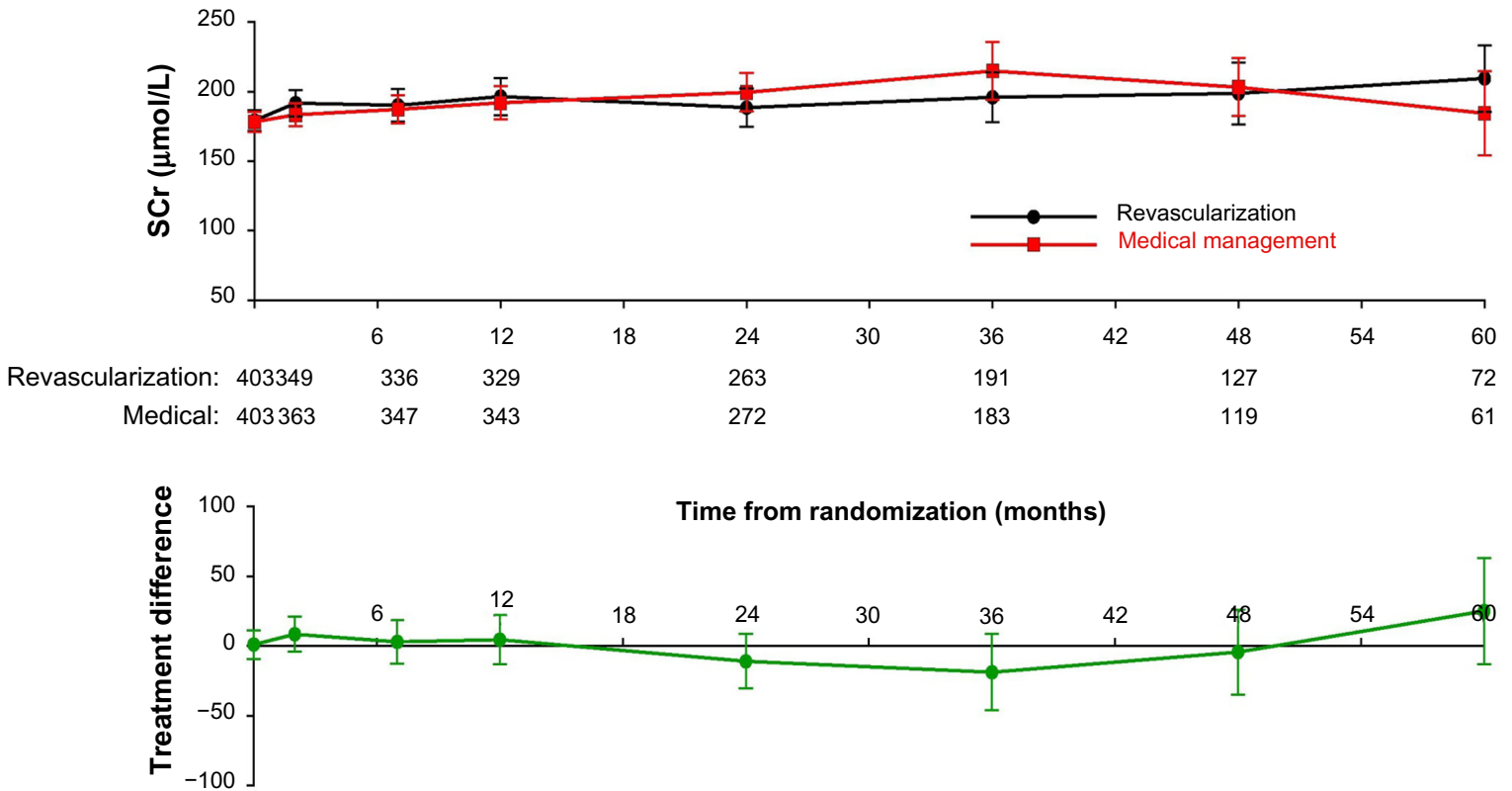

Figure 2 Mean serum creatinine $(\mu \mathrm{mol} / \mathrm{L})$ over time (repeated measures analysis) with revascularization and medical therapy in ASTRAL.

Note: Data from the ASTRAL study. ${ }^{8}$

Abbreviations: ASTRAL, Angioplasty and STenting for Renal Artery Lesions; SCr, serum creatinine. 
Valluri et al ${ }^{53}$ were only able to demonstrate a suggestion of benefit in those with rapidly deteriorating renal function, and this was not statistically significant. There was no improvement in cardiovascular outcomes or mortality. However, the authors failed to account for use of angiotensin blockade post-intervention, which may have confounded the results.

A recent single-center retrospective analysis looked at different clinical presentations of ARVD. A total of 467 cases of patients with $>50 \%$ unilateral RAS were reviewed, inclusive of those enrolled in clinical trials. High-risk clinical presentations were defined as flash pulmonary edema, refractory hypertension, and rapidly declining renal function. The 237 patients with high-risk presentations were compared with the 230 patients with none of these features. The authors demonstrated a mortality benefit in those patients who presented with flash pulmonary edema and underwent revascularization compared with those with the same clinical presentation who had no radiological intervention (hazard ratio $0.4,95 \%$ CI $0.2-0.9 ; P=0.01)$. When considered in combination, there was a benefit in terms of mortality and cardiovascular events in those with both rapidly declining renal function and refractory hypertension undergoing revascularization compared with those with no intervention, but such positive results were not seen for either clinical presentation occurring alone. There was no benefit in terms of rate of decline in renal function in any group. ${ }^{14}$ Although there are limitations to this retrospective data, the results help to ascertain the benefits of revascularization in terms of mortality and cardiovascular events in patients with high-risk presentations. It also questions the utility of change in renal function as a clinical endpoint in ARVD. Perhaps further studies will shed more light on the utility of revascularization as a treatment to improve renal function or maybe it is now time to consider different clinical endpoints and to focus on a better description of the population likely to benefit from revascularization in ARVD.

In order to determine whether the subgroup of patients with rapidly deteriorating renal function are likely to benefit from revascularization, a patient-level meta-analysis of ASTRAL, CORAL, and STAR will most probably be needed.

\section{Developments in revascularization}

There appears to be no universal benefit of revascularization in ARVD, and there are significant risks associated with interventional procedures. This has led to a number of studies focusing on ways to predict or enhance individual response to intervention.
A meta-analysis of studies in ARVD found no clinical characteristics that were able to reliably predict outcomes following revascularization. ${ }^{54}$ However, a number of studies have looked at other ways of predicting response to revascularization in ARVD, either through imaging techniques or biomarker measurement.

Cheung et $\mathrm{al}^{55}$ looked at parenchymal volume assessed via magnetic resonance imaging (MRI) scanning and isotopic single kidney glomerular filtration rate (GFR) in 50 patients with $>50 \%$ RAS who underwent revascularization plus medical therapy or medical therapy alone. In their study, a disproportionately high ratio of parenchymal volume to single-kidney GFR (PV:SKGFR - a possible reflection of 'hibernating parenchyma') was predictive of improvement in GFR post-revascularization. Although clinicians may take note of renal size in deciding the potential benefit of revascularization for an individual, there is no routine assessment of renal reserve.

Other imaging techniques have shown variable promise in determining which individuals may benefit from revascularization. It has been suggested that determination of renal resistive index with duplex Doppler ultrasound scanning may indicate response to revascularization. ${ }^{56,57}$

Blood oxygen level-dependent (BOLD) magnetic resonance scanning has been developed as a noninvasive investigation that may help predict response to revascularization. It is a sensitive technique to detect changes in tissue deoxyhemoglobin. Animal studies have shown that BOLD imaging reliably detects changes in intra-renal oxygenation with varying degrees of reduction in renal blood flow. ${ }^{58}$ A clinical study of 28 patients demonstrated that high BOLD signal to single kidney isotopic GFR was predictive of improvement in renal function following revascularization, ${ }^{59}$ thereby suggesting that BOLD imaging may provide a way of again detecting so-called 'hibernating parenchyma.'

Various other studies have looked for factors that may help predict response to revascularization in individuals. A small study $(n=27)$ by Silva et $\mathrm{l}^{60}$ measured pre- and post-intervention brain natriuretic peptide (BNP) levels and blood pressure response to endovascular revascularization. Pre-intervention BNP levels of $>80 \mathrm{pg} / \mathrm{mL}$ were predictive of a response to revascularization $(P=0.001)$. However, the small study numbers and specified endpoint of the analysis should caution extrapolation of these results pending further research.

One explanation for why renal function does not consistently improve following renal revascularization is that cholesterol micro-embolization may accompany 
the procedure. In an RCT of 100 patients undergoing percutaneous revascularization procedures for RAS, there was a post-procedure fall in estimated GFR (eGFR) in all patients, regardless of whether or not an embolic protection device was deployed or the glycoprotein IIb/IIIa inhibitor abciximab was administered. However, with combination therapy, no post-procedure fall in eGFR was observed, ${ }^{61}$ suggesting a potential benefit for such therapies in ameliorating cholesterol embolization post-intervention.

In the context of ischemia, neovascularization within the microvasculature occurs to sustain tissue perfusion. ${ }^{62}$ The microvasculature maintains plasticity and is able to regulate angiogenesis in response to changes in local metabolic requirements. ${ }^{63}$ Vascular endothelial growth factor (VEGF) is secreted in response to acute hypoxia and is essential for the preservation of this microvasculature ${ }^{64}$ However, in the context of prolonged hypoxia, VEGF secretion is diminished, ${ }^{65}$ presumably because injured cells are no longer able to secrete this cytokine. This leads to a cascade of poor microvascular repair and increasing renal injury. In animal studies, administration of VEGF prior to revascularization improved postprocedure blood pressure and renal function. This was felt to be due to improvements in the renal microcirculation. ${ }^{20}$

\section{Revascularization for other causes of RAS}

ARVD is the leading cause of RAS in the Western world, followed by fibromuscular dysplasia. In contrast, vasculitic disease (invariably Takayasu's arteritis) is the most common cause in South-East Asia. Other diseases, such as middle aortic syndrome, embolic phenomenon, and arterial dissection are important, albeit less common, causes of RAS. Hypertension is generally a more significant clinical problem than renal dysfunction in these conditions. In fibromuscular dysplasia and Takayasu's disease, evidence for benefit from revascularization is more consistent than in ARVD, but this is due, at least in part, to the fact that control of hypertension is the main treatment goal, and robust trials are still lacking.

\section{Fibromuscular dysplasia}

Fibromuscular dysplasia is a non-atherosclerotic noninflammatory condition that most commonly affects women aged 15-60 years. The most usual presentation is with renovascular hypertension, although stroke and cranial nerve palsies are well recognized and it can affect any arterial bed in the body. There are no RCT data to guide management in this condition, and the prospective studies that do exist report widely varying success in terms of successful control of hypertension and recurrence of stenotic lesion. ${ }^{66} \mathrm{~A}$ meta-analysis and systematic review of 70 studies reported a $46 \%$ (95\% CI 40-52) cure rate with angioplasty, with the greatest success observed amongst young patients with a short duration of hypertension and where there was successful obliteration of the pressure gradient with treatment. ${ }^{67}$ It is possible that co-existence of essential hypertension in older patients reduced the success of revascularization procedures in these studies. Revascularization is recommended as first-line therapy for young patients ${ }^{68}$ and those with severe disease, refractory hypertension, or deteriorating renal function. ${ }^{69}$ In contrast to ARVD, the main focus is management of hypertension rather than preventing the decline of renal function, and revascularization is usually by balloon angioplasty without the need for stent insertion.

\section{Vasculitis}

Immunosuppressive therapy is indicated in the treatment of the acute phase of Takayasu's vasculitis, and there is no role for revascularization at this stage. As the disease moves into the chronic stenotic phase, patients are often hypertensive and may have impaired renal function or heart failure as a consequence of arterial stenosis. A retrospective review of 66 patients treated with revascularization reported a cure of hypertension in around $25 \%$ of patients and large reductions in blood pressure $(45 / 22 \mathrm{mmHg})$ and need for anti-hypertensive medications in the remainder, with around a $60 \%-90 \%$ technical success rate. ${ }^{70} \mathrm{~A}$ further prospective study of 27 patients with Takayasu's-induced RAS reported an improvement in mean eGFR from $76 \mathrm{~mL} / \mathrm{min}$ to $88 \mathrm{~mL} / \mathrm{min}(P<0.005)$ following revascularization, and two patients were able to discontinue hemodialysis due to recovery of renal function. There were improvements in blood pressure in all patients, and of congestive cardiac failure symptoms in the latter two affected patients. ${ }^{71}$ Although this remains a rare disease, and study numbers are very small, there is a suggestion that revascularization procedures are more likely to lead to an improvement in renal function than in ARVD. The complex etiology of ARVD, with oxidative stress, inflammation, and microvascular disruption all contributing to renal decline, may help to explain this disparity.

\section{Conclusion}

There is reasonable evidence to support revascularization as a treatment to improve renal function and hypertension in fibromuscular dysplasia and in RAS following inflammatory arteritis. The situation is certainly much less clear in ARVD. Here, medical therapy remains the cornerstone of treatment and vascular risk factors should be aggressively targeted. 
Although questions remain, there seems to be little benefit from revascularization in ARVD, and this should be balanced against the procedural risks in each individual patient.

ARVD is not a disease limited to the renal arteries, but reflects a diffuse process of atherosclerosis and aging. The degree of RAS is a smaller determinant of renal function than the parenchymal injury resulting from atherosclerotic processes of oxidative stress, inflammation, and fibrosis. Established parenchymal damage is often irreversible, so the goal of treatment in ARVD is to limit further renal injury. In this regard, renal function may not be the best endpoint for intervention in ARVD. It is hoped that further analyses will provide clearer guidance as to which patients are most likely to benefit from revascularization procedures, but certainly treatment should be individualized and it should be accepted that there is no single treatment suitable for all in ARVD.

\section{Disclosure}

Philip A Kalra was a co-author of the ASTRAL trial. The authors report no other conflicts of interest in this work.

\section{References}

1. de Mast Q, Beutler JJ. The prevalence of atherosclerotic renal artery stenosis in risk groups: a systematic literature review. J Hypertens. 2009;27(7):1333-1340.

2. Hansen KJ, Edwards MS, Craven TE, et al. Prevalence of renovascular disease in the elderly: a population-based study. J Vasc Surg. 2002;36(3):443-451.

3. Kalra PA, Guo H, Kausz AT, et al. Atherosclerotic renovascular disease in United States patients aged 67 years or older: risk factors, revascularization, and prognosis. Kidney Int. 2005;68(1):293-301.

4. Kalra PA, Guo H, Gilbertson DT, et al. Atherosclerotic renovascular disease in the United States. Kidney Int. 2010;77(1):37-43.

5. Collins AJ, Foley RN, Herzog C, et al. Excerpts From the US Renal Data System 2009 Annual Data Report. Am J Kidney Dis. 2010; 55(1 Suppl 1):S1-S420, A6-A7.

6. Jazrawi A, Darda S, Burke P, et al. Is race a risk factor for the development of renal artery stenosis? Cardiol Res Pract. 2009;2009:817987.

7. Kawarada O, Yokoi Y, Morioka N, Takemoto K. Renal artery stenosis in cardio- and cerebrovascular disease: renal duplex ultrasonography as an initial screening examination. Circ J. 2007;71(12):1942-1947.

8. ASTRAL Investigators, Wheatley $\mathrm{K}$, Ives $\mathrm{N}$, et al. Revascularization versus medical therapy for renal-artery stenosis. N Engl J Med. 2009; 361(20):1953-1962.

9. Conlon PJ, Little MA, Pieper K, Mark DB. Severity of renal vascular disease predicts mortality in patients undergoing coronary angiography. Kidney Int. 2001;60(4):1490-1497.

10. Amighi J, Schlager O, Haumer M, et al. Renal artery stenosis predicts adverse cardiovascular and renal outcome in patients with peripheral artery disease. Eur J Clin Invest. 2009;39(9):784-792.

11. Shurrab AE, MacDowall P, Wright J, Mamtora H, Kalra PA. The importance of associated extra-renal vascular disease on the outcome of patients with atherosclerotic renovascular disease. Nephron Clin Pract. 2003;93(2):C51-C57.

12. Mailloux LU, Napolitano B, Bellucci AG, Vernace M, Wilkes BM, Mossey RT. Renal vascular disease causing end-stage renal disease, incidence, clinical correlates, and outcomes: a 20-year clinical experience. Am J Kidney Dis. 1994;24(4):622-629.
13. Guo H, Kalra PA, Gilbertson DT, et al. Atherosclerotic renovascular disease in older US patients starting dialysis, 1996 to 2001. Circulation. 2007;115(1):50-58.

14. Ritchie J, Green D, Chrysochou C, Chalmers N, Foley RN, Kalra PA. High-risk clinical presentations in atherosclerotic renovascular disease: prognosis and response to renal artery revascularization. Am J Kidney Dis. Epub September 26, 2013.

15. Chrysochou C, Kalra PA. Epidemiology and natural history of atherosclerotic renovascular disease. Prog Cardiovasc Dis. 2009;52(3): 184-195.

16. Farrington K, Udayaraj U, Gilg J, Feehally J. UK Renal Registry 11th Annual Report (December 2008): Chapter 3 ESRD incident rates in 2007 in the UK: National and centre-specific analyses. Nephron Clin Pract. 2009;111 Suppl 1:c13-c41.

17. Schreiber MJ, Pohl MA, Novick AC. The natural history of atherosclerotic and fibrous renal artery disease. Urol Clin North Am. 1984;11(3): 383-392.

18. Crowley JJ, Santos RM, Peter RH, et al. Progression of renal artery stenosis in patients undergoing cardiac catheterization. Am Heart J. 1998;136(5):913-918.

19. Cheung CM, Wright JR, Shurrab AE, et al. Epidemiology of renal dysfunction and patient outcome in atherosclerotic renal artery occlusion. J Am Soc Nephrol. 2002;13(1):149-157.

20. Chade AR, Kelsen S. Renal microvascular disease determines the responses to revascularization in experimental renovascular disease. Circ Cardiovasc Interv. 2010;3(4):376-383.

21. Caps MT, Zierler RE, Polissar NL, et al. Risk of atrophy in kidneys with atherosclerotic renal artery stenosis. Kidney Int. 1998;53(3): 735-742.

22. Tuttle K. Renal parenchymal injury as a determinant of clinical consequences in atherosclerotic renal artery stenosis. Am J Kidney Dis. 2002;39(6):1321-1322.

23. Chrysochou C, Foley RN, Young JF, Khavandi K, Cheung CM, Kalra PA. Dispelling the myth: the use of renin-angiotensin blockade in atheromatous renovascular disease. Nephrol Dial Transpl. 2012;27(4):1403-1409.

24. Hackam DG, Duong-Hua ML, Mamdani M, et al. Angiotensin inhibition in renovascular disease: a population-based cohort study. Am Heart J. 2008;156(3):549-555.

25. Cheung CM, Patel A, Shaheen N, et al. The Effects of Statins on the Progression of Atherosclerotic Renovascular Disease. Nephron Clin Pract. 2007;107(2):c35-c42.

26. Cooper CJ, Murphy TP, Matsumoto A, et al. Stent revascularization for the prevention of cardiovascular and renal events among patients with renal artery stenosis and systolic hypertension: rationale and design of the CORAL trial. Am Heart J. 2006;152(1):59-66.

27. Weibull H, Bergqvist D, Bergentz SE, Jonsson K, Hulthén L, Manhem P. Percutaneous transluminal renal angioplasty versus surgical reconstruction of atherosclerotic renal artery stenosis: a prospective randomized study. J Vasc Surg. 1993;18(5):841-852.

28. Modrall JG, Rosero EB, Smith ST, et al. Operative mortality for renal artery bypass in the United States: results from the National Inpatient Sample. J Vasc Surg. 2008;48(2):317-322.

29. Harden PN, MacLeod MJ, Rodger RS, et al. Effect of renal-artery stenting on progression of renovascular renal failure. Lancet. 1997; 349(9059):1133-1136.

30. Zeller T, Frank U, Müller C, et al. Predictors of improved renal function after percutaneous stent-supported angioplasty of severe atherosclerotic ostial renal artery stenosis. Circulation. 2003;108(18):2244-2249.

31. van de Ven PJ, Kaatee R, Beutler JJ, et al. Arterial stenting and balloon angioplasty in ostial atherosclerotic renovascular disease: a randomised trial. Lancet. 1999;353(9149):282-286.

32. Leertouwer TC, Gussenhoven EJ, Bosch JL, et al. Stent placement for renal arterial stenosis: where do we stand? A meta-analysis. Radiology. 2000;216(1):78-85.

33. NHS IC. United Kingdom Hospital Episode Statistics. Available from: http://www.hscic.gov.uk/hes. Accessed September 22, 2013. 
34. Hirsch AT, Haskal ZJ, Hertzer NR, et al. ACC/AHA Guidelines for the management of patients with peripheral arterial disease (lower extremity, renal, mesenteric, and abdominal aortic): a collaborative report from the American Associations for Vascular Surgery/Society for Vascular Surgery, Society for Cardiovascular Angiography and Interventions, Society for Vascular Medicine and Biology, Society of Interventional Radiology, and the ACC/AHA Task Force on Practice Guidelines (writing committee to develop guidelines for the management of patients with peripheral arterial disease): summary of recommendations. J Vasc Interv Radiol. 2006;17(9):1383-1397; quiz 1398.

35. Messina LM, Zelenock GB, Yao KA, Stanley JC. Renal revascularization for recurrent pulmonary edema in patients with poorly controlled hypertension and renal insufficiency: a distinct subgroup of patients with arteriosclerotic renal artery occlusive disease. JVasc Surg. 1992;15(1): 73-82.

36. Chrysochou C, Sinha S, Chalmers N, Kalra PR, Kalra PA. Anuric acute renal failure and pulmonary oedema: a case for urgent action. Int $J$ Cardiol. 2009;132(1):e31-e33.

37. Dear JW, Padfield PL, Webb DJ. New guidelines for drive-by renal arteriography may lead to an unjustifiable increase in percutaneous intervention. Heart. 2007;93(12):1528-1532.

38. Goldsmith DJ, Reidy J, Scoble J. Renal arterial intervention and angiotensin blockade in atherosclerotic nephropathy. Am J Kidney Dis. 2000;36(4):837-843.

39. Kane GC, Xu N, Mistrik E, Roubicek T, Stanson AW, Garovic VD. Renal artery revascularization improves heart failure control in patients with atherosclerotic renal artery stenosis. Nephrol Dial Transpl. 2010; 25(3):813-820.

40. Watson PS, Hadjipetrou P, Cox SV, Piemonte TC, Eisenhauer AC. Effect of renal artery stenting on renal function and size in patients with atherosclerotic renovascular disease. Circulation. 2000;102(14): 1671-1677.

41. Isles CG, Robertson S, Hill D. Management of renovascular disease: a review of renal artery stenting in ten studies. QJM. 1999;92(3): $159-167$.

42. Dejani H, Eisen TD, Finkelstein FO. Revascularization of renal artery stenosis in patients with renal insufficiency. Am J Kidney Dis. 2000;36(4):752-758.

43. Beutler JJ, Van Ampting JM, Van De Ven PJ, et al. Long-term effects of arterial stenting on kidney function for patients with ostial atherosclerotic renal artery stenosis and renal insufficiency. J Am Soc Nephrol. 2001;12(7):1475-1481.

44. Plouin PF, Chatellier G, Darné B, Raynaud A. Blood pressure outcome of angioplasty in atherosclerotic renal artery stenosis: a randomized trial. Essai Multicentrique Medicaments vs Angioplastie (EMMA) Study Group. Hypertension. 1998;31(3):823-829.

45. van Jaarsveld BC, Krijnen P, Pieterman H, et al. The effect of balloon angioplasty on hypertension in atherosclerotic renal-artery stenosis. N Engl J Med. 2000;342(14):1007-1014.

46. Webster J, Marshall F, Abdalla M, et al. Randomised comparison of percutaneous angioplasty vs continued medical therapy for hypertensive patients with atheromatous renal artery stenosis. Scottish and Newcastle Renal Artery Stenosis Collaborative Group. J Hum Hypertens. 1998; 12(5):329-335.

47. Bax L, Woittiez AJ, Kouwenberg HJ. Stent placement in patients with atherosclerotic renal artery stenosis and impaired renal function: a randomized trial. Ann Intern Med. 2009;150(12):840-848.

48. Ives NJ, Wheatley K, Stowe RL, et al. Continuing uncertainty about the value of percutaneous revascularization in atherosclerotic renovascular disease: a meta-analysis of randomized trials. Nephrol Dial Transpl. 2003;18(2):298-304.

49. George JC, White CJ. Renal artery stenting: lessons from ASTRAL (Angioplasty and Stenting for Renal Artery Lesions). JACC CardiovasC Interv. 2010;3(7):786-787.

50. White CJ. Kiss my astral: one seriously flawed study of renal stenting after another. Catheter Cardiovasc Interv. 2010;75(2):305-307.
51. Chalmers N, Moss J, Nicholson AA. "Re: renal artery stenting is no longer indicated after ASTRAL: pros and cons." Cardiovasc Intervent Radiol. 2011;34(2):252-253.

52. Cooper CJ, Murphy TP, Cutlip DE, et al. Stenting and medical therapy for atherosclerotic renal-artery stenosis. $N$ Engl J Med. Epub November 18, 2013.

53. Valluri A, Severn A, Chakraverty S. Do patients undergoing renal revascularization outside of the ASTRAL trial show any benefit? Results of a single-centre observational study. Nephrol Dial Transpl. 2012;27(2):734-738.

54. Ronden RA, Houben AJ, Kessels AG, Stehouwer CD, de Leeuw PW, Kroon AA. Predictors of clinical outcome after stent placement in atherosclerotic renal artery stenosis: a systematic review and meta-analysis of prospective studies. J Hypertens. 2010;28(12):2370-2377.

55. Cheung CM, Chrysochou C, Shurrab AE, Buckley DL, Cowie A, Kalra PA. Effects of renal volume and single-kidney glomerular filtration rate on renal functional outcome in atherosclerotic renal artery stenosis. Nephrol Dial Transpl. 2010;25(4):1133-1140.

56. Radermacher J, Chavan A, Bleck J, et al. Use of Doppler ultrasonography to predict the outcome of therapy for renal-artery stenosis. $N$ Engl J Med. 2001;344(6):410-417.

57. Zeller T, Frank U, Späth M, Roskamm H. [Color duplex ultrasound imaging of renal arteries and detection of haemodynamically relevant renal artery stenosis]. Ultraschall Med. 2001;22(3):116-121. German.

58. Juillard L, Lerman LO, Kruger DG, et al. Blood oxygen leveldependent measurement of acute intra-renal ischemia. Kidney Int. 2004;65(3):944-950.

59. Chrysochou C, Mendichovszky IA, Buckley DL, Cheung CM, Jackson A, Kalra PA. BOLD imaging: a potential predictive biomarker of renal functional outcome following revascularization in atheromatous renovascular disease. Nephrol Dial Transpl. 2012;27(3):1013-1019.

60. Silva JA, Chan AW, White CJ, et al. Elevated brain natriuretic peptide predicts blood pressure response after stent revascularization in patients with renal artery stenosis. Circulation. 2005;111(3):328-333.

61. Cooper CJ, Haller ST, Colyer W, et al. Embolic protection and platelet inhibition during renal artery stenting. Circulation. 2008;117(21):2752-2760

62. Chade AR, Krier JD, Galili O, Lerman A, Lerman LO. Role of renal cortical neovascularization in experimental hypercholesterolemia. Hypertension. 2007;50(4):729-736.

63. Lévy BI. Microvascular plasticity and experimental heart failure. Hypertension. 2006;47(5):827-829.

64. Nakagawa T, Lan HY, Zhu HJ, Kang DH, Schreiner GF, Johnson RJ. Differential regulation of VEGF by TGF-beta and hypoxia in rat proximal tubular cells. Am J Physiol Renal Physiol. 2004;287(4):F685-F664.

65. Olszewska-Pazdrak B, Hein TW, Olszewska P, Carney DH. Chronic hypoxia attenuates VEGF signaling and angiogenic responses by downregulation of KDR in human endothelial cells. Am J Physiol Cell Physiol. 2009;296(5):C1162-C1170.

66. Slovut DP, Olin JW. Fibromuscular dysplasia. N Engl J Med. 2004; 350(18):1862-1871.

67. Trinquart L, Mounier-Vehier C, Sapoval M, Gagnon N, Plouin PF. Efficacy of revascularization for renal artery stenosis caused by fibromuscular dysplasia: a systematic review and meta-analysis. Hypertension. 2010;56(3):525-532.

68. Olin JW, Sealove BA. Diagnosis, management, and future developments of fibromuscular dysplasia. J Vasc Surg. 2011;53(3):826-836. e1.

69. Plouin PF, Perdu J, La Batide-Alanore A, Boutouyrie P, GimenezRoqueplo A-P, Jeunemaitre X. Fibromuscular dysplasia. Orphanet $J$ Rare Dis. 2007;2:28.

70. Sharma S, Gupta H, Saxena A, et al. Results of renal angioplasty in nonspecific aortoarteritis (Takayasu disease). J Vasc Interv Radiol. 1998;9(3):429-435.

71. Weaver FA, Kumar SR, Yellin AE, et al. Renal revascularization in Takayasu arteritis-induced renal artery stenosis. J Vasc Surg. 2004;39(4):749-757. 


\section{Publish your work in this journal}

The International Journal of Nephrology and Renovascular Disease is an international, peer-reviewed open-access journal focusing on the pathophysiology of the kidney and vascular supply. Epidemiology, screening, diagnosis, and treatment interventions are covered as well as basic science, biochemical and immunological studies. The journal welcomes original research, clinical studies, reviews \& evaluations, expert opinion and commentary, case reports and extended reports. The manuscript management system is completely online and includes a very quick and fair peerreview system, which is all easy to use. Visit http://www.dovepress.com/ testimonials.php to read real quotes from published authors

Submit your manuscript here: http://www.dovepress.com/international-journal-of-nephrology-and-renovascular-disease-journal 